\title{
UNA NUEVA ESPECIE ARBOREA DE LA FAMILIA MALVACEAE
}

Robinsonella mirandai sp. nov.

\author{
Arturo Gómez Pompa *
}

Arbor usque $30 \mathrm{~m}$. alta. Folia petiolis magnis $6-10 \mathrm{~cm}$. longis; lamina chartacea supra atroviridis, subtus alba, subcordata vel subdeltoidea, 10-17 cm. longa, 8-15 cm. lata, apice acuminato, basi subcordata vel truncata, margine integra vel parce undulata, subtus conspicue stellato-tomentosa, supra inconspicue stellato-puberula. Inflorescentiae breves, axillares, paniculatae, 2-4 flores pedicellis circa dimidium articulatis, stellato-tomentosis, 1-5 cm. longis; sepala stellato-tomentosa, concava, 6-8 mm. longa, 4-5 mm. lata; petala ovata vel ovato-orbiculata, extremis albis et basi purpurea, 5-8 $\mathrm{mm}$. longa, $5 \mathrm{~mm}$. lata, pilis-stellatis, longis, versus interna basis; columna staminalis $5 \mathrm{~mm}$. longa, tubulata, minutissime stellatopuberula; stamina filamentis superne liberis, circa $5 \mathrm{~mm}$. exsertis; ovarium carpelis 12, minutissime stellato-puberulum; schizocarpium 2-3 cm. latum, $5 \mathrm{~mm}$. minusve altum, merocarpia 12, $1 \mathrm{~cm}$. longa, $3 \mathrm{~mm}$. Lata, minutissime stellato-puberula.

Arbol hasta de $30 \mathrm{~m}$. de alto con su tronco grueso de $2 \mathrm{~m}$. cuando más de circunferencia; presenta contrafuertes pequeños; corteza de color gris, frecuentemente agrietada. Hojas con peciolos grandes de 6 a $10 \mathrm{~cm}$. de largo, más o menos estelados puberulentos; lámina cartacea de color verde oscuro en el haz y blanco en el envés, subcordada o subdeltoidea, de 10 a $17 \mathrm{~cm}$. de largo por 8 a $15 \mathrm{~cm}$. de ancho, ápice acuminado, base subcordada o truncada, borde entero o algo ondulado. Conspicuamente estelado-tomentosa en el envés, con pelos largos también estrellados hacia la unión con el peciolo, e inconspicuamente estelado-puberulenta en el haz; siete nervios principales, promínulos en el envés, poco ramificados.

Inflorescencias cortas axilares paniculadas, de 2 a 4 flores con pedicelos articulados hacia la mitad, estelado-tomentosos, de $1.5 \mathrm{~cm}$. de largo; sépalos estelado-tomentosos de color verde, ovales, cóncavos, de 6 a 8 $\mathrm{mm}$. de largo por 4 a $5 \mathrm{~cm}$. de ancho; pétalos ovales u ovado-orbiculares, blancos en los extremos y púrpuras en la base, de 5 a $8 \mathrm{~mm}$. de largo por $5 \mathrm{~mm}$. de ancho, con pelos estrellados largos hacia la parte interior de la base; columna estaminal de $5 \mathrm{~mm}$. de largo, tubular, finamente estelado-pulverulenta; estambres con filamentos libres en la parte superior sobresaliendo unos $5 \mathrm{~mm}$; ovario con 12 carpelos finamente estelado pulverulento; fruto, un esquizocarpio de 2 a $3 \mathrm{~cm}$. de ancho, por $5 \mathrm{~mm}$. o menos de alto, merocarpios 12, de $1 \mathrm{~cm}$. de largo por $3 \mathrm{~mm}$. de ancho, finamente estelados, pulverulentos.

* Comisión de dioscoreas en el Instituto Nacional de Investigaciones Forestales.

Industria Nacional Químico Farmacéutica.

Gómez-Pompa A. 1962. Una nueva especie arbórea de la familia Malvaceae. Boletín de la Sociedad Botánica de México 27: 37-41. 
Tipo en el Herbario del Instituto de Biología, Univ. Méx.; Veracruz: Chichipilco, en las faldas del Volcán San Martín, San Andrés Tuxtla, Ver.; en selva alta perennifolia a unos $800 \mathrm{~m}$. de altitud, col. Jesús Vázquez Soto No. 21 (1o. de Dic. 1960; flores y frutos).

Otros ejemplares; Oaxaca: entre Chiltepec y Valle Nacional; en selva alta perennifolia sobre la base de cerros con rocas calizas, a unos $300 \mathrm{~m}$. de altitud, col. A. Gómez Pompa y L. Hernández Pallares s. n. (Nov. de 1959, con flores).

Esta especie es afín a Robinsonella discolor, distinguiéndose de ella en ser sus individuos adultos más grandes, generalmente enormes, de 20 o más metros de alto, así como en sus hojas adultas que tienen el borde entero o muy ligeramente ondulado, contrastando con $R$. discolor cuyas hojas adultas, tienen bordes ondulado-dentados e inclusive algo trilobuladas.

Las flores son más pequeñas en Robinsonella mirandai (pétalos de 5 a $8 \mathrm{~mm}$. de largo) que en Robinsonella discolor (pétalos de 10 a $14 \mathrm{~mm}$. de largo), así como la columna estaminal es delgada y tubiforme en la primera, en cambio es de forma cónica en la segunda.

Esta especie nueva es de un interés muy grande, pues es dominante en muchas selvas del Estado de Veracruz y Oaxaca. Se ha encontrado también en la región de Córdoba, Ver., siendo muy abundante en las selvas que habitan los cerros con rocas calizas de naturaleza carstica, sobre suelos someros de color moreno oscuro con abundante materia orgánica. En este mismo tipo de suelo existe desde Temascal hasta Valle Nacional (Oax.) sobre todo en las partes bajas de dichos cerros en donde el suelo es algo más profundo. Sólo en la región de los Tuxtlas, Ver., es algo diferente el lugar donde se encuentra, pues se le ha visto sobre cerros, pero en suelos de color moreno oscuro de origen volcánico (cenizas), e incluso en planicies con muy ligera inclinación.

Esta especie recibe los nombres vulgares de "majagua blanca", (Temascal a Valle Nacional), "algodoncillo" (Los Tuxtlas, Ver.), y "manzanillo" (Córdoba, Ver.).

La especie ha sido dedicada al doctor Faustino Miranda, eminente investigador que ha dedicado gran parte de su vida al estudio de las regiones tropicales cálidas mexicanas, y en especial a los árboles que viven en dichas zonas. 


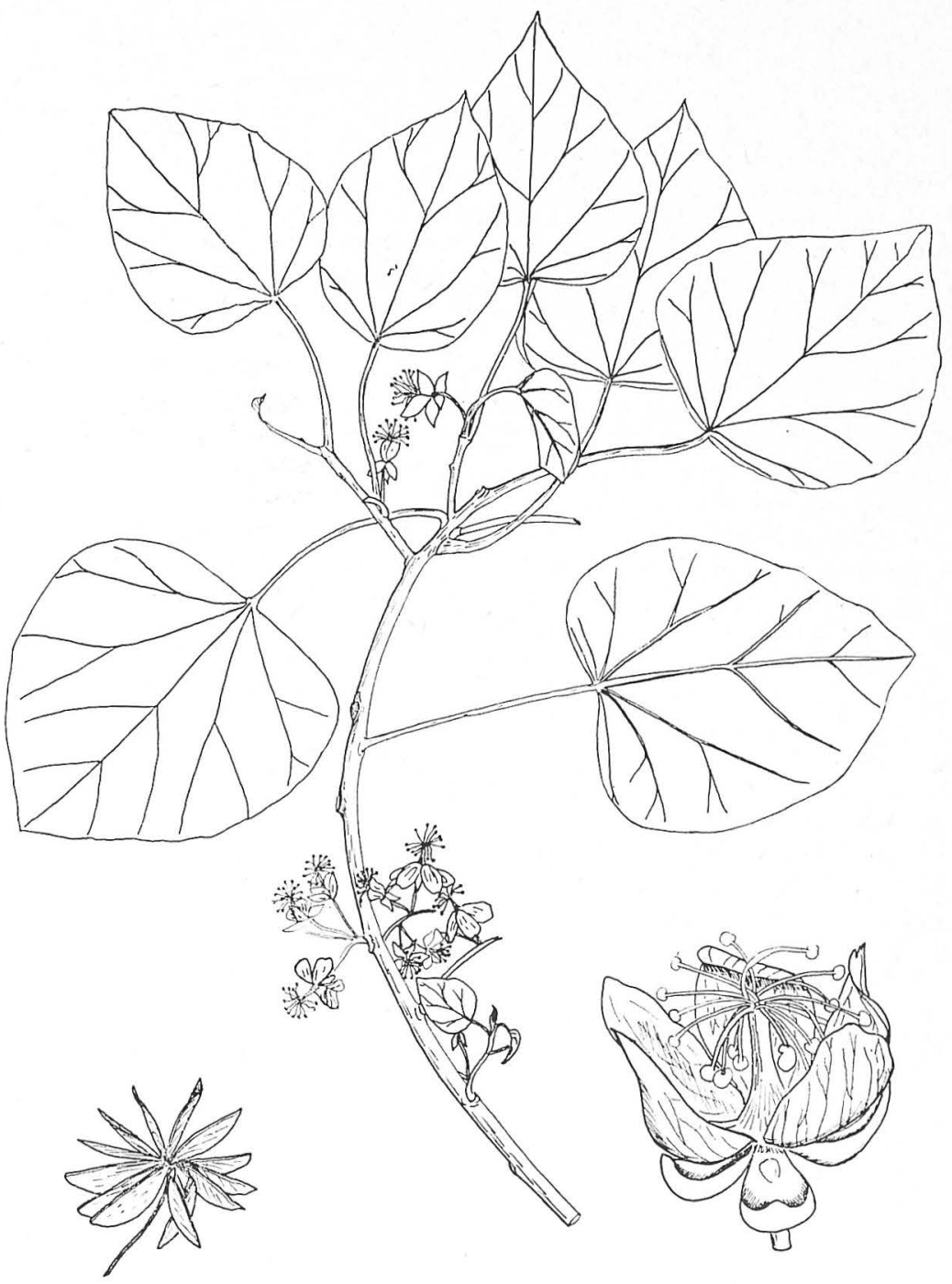

FIG. 1. Robinsonella mirandai. Rama con flores y hojas, asi como una flor y un fruto ר mayor tamaño. (Dib. R. Riba). 


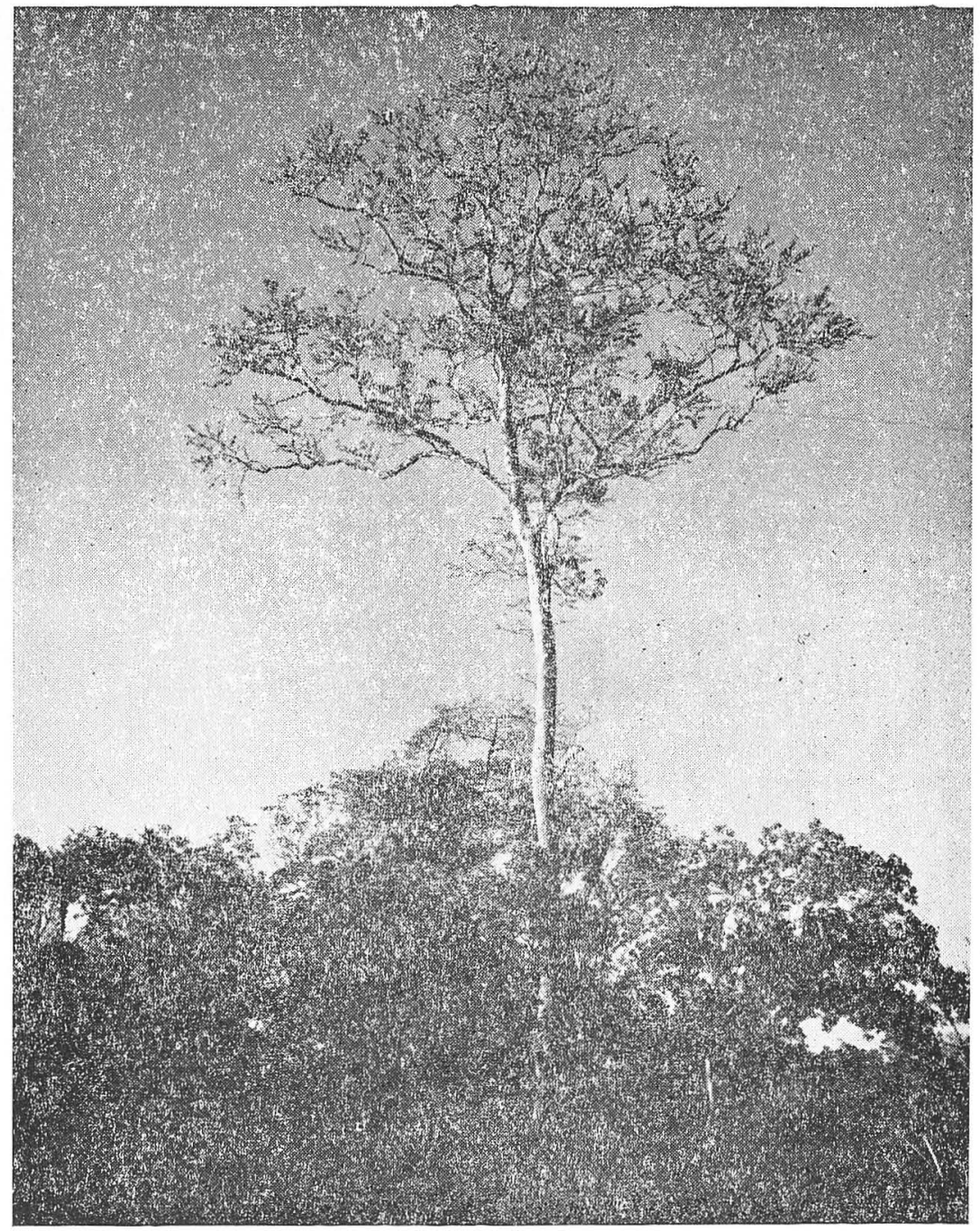

FIG. 2. Robinsonella mirandai, en la región de los Tuxtlas, Ver. (Foto Sr. Maya, U. N. A. M.). 


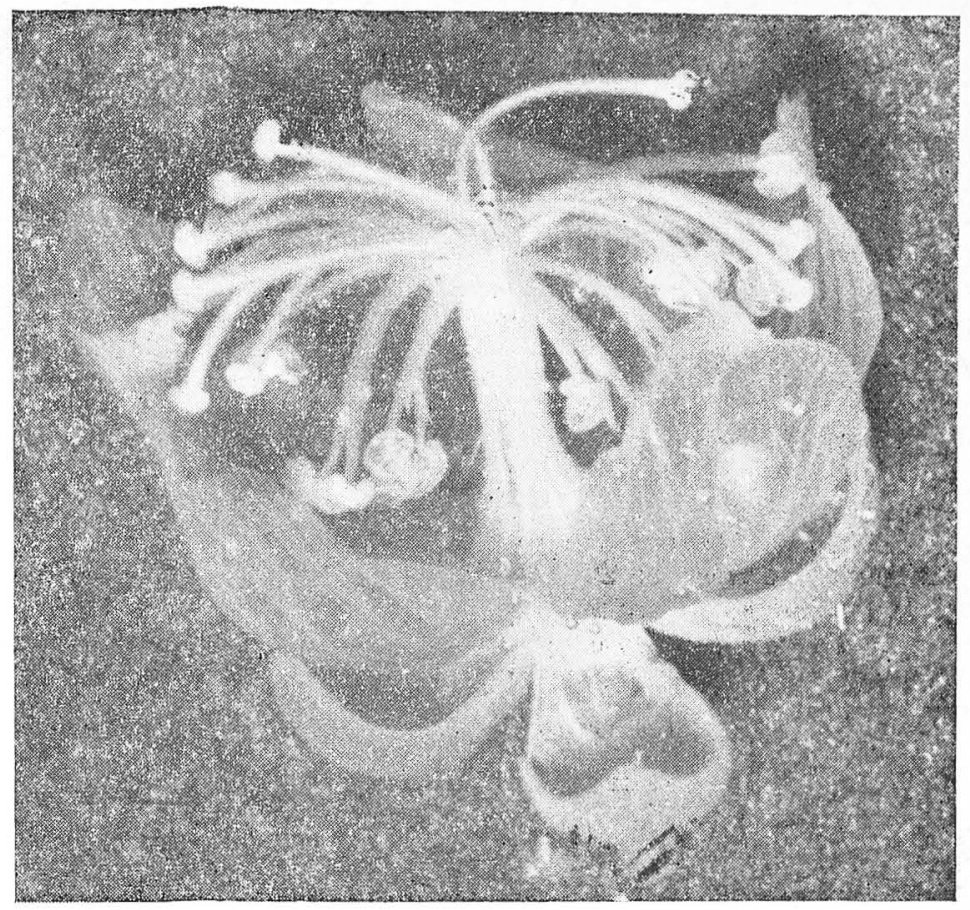

FIG. 3. Robinsonella mirandai. Flor amplificada. 